\title{
E1 Estado absolutista y la reforma protestante como el umbral de la biopolitica
}

\section{The absolutist state and the Protestant reform as the threshold of biopolitics}

\section{Rodrigo Hernández Gamboa iD}

Universidad Autónoma Metropolitana, México

arcadios23@gmail.com

\begin{abstract}
Resumen
El objetivo de este artículo es analizar los elementos que permitieron el desarrollo de las prácticas biopoliticas por los Estados modernos. Desde el método hermenéutico este texto recoge la confrontación entre el poder eclesiástico y el poder soberano en la Edad Media para legitimar su autoridad sobre los individuos, situación que permitió el establecimiento del Estado absolutista y la búsqueda por gestionar la vida biológica de los individuos desde la esfera pública. Este escenario se consolidó con la reforma protestante y la búsqueda desde el Estado por generar los mecanismos para recuperar la paz y la seguridad entre sus súbditos, asentando los pilares de las prácticas biopolíticas en la modernidad.
\end{abstract}

Palabras clave: poder eclesiástico, poder politico, biopoder, Estado, cristianismo.

\begin{abstract}
This article aims to analyze the elements that allowed the development of biopolitical practices by modern States. From the hermeneutical method, this text includes the confrontation between ecclesiastical power and sovereign power in the Middle Ages to legitimize their authority over individuals, a situation that will lead to the establishment of the absolutist state and the search to manage the biological life of individuals from the beginning. public sphere. This scenario was consolidated with the Protestant reform and the search from the State to generate the mechanisms to regain peace and security among its subjects, establishing the pillars of biopolitics in modernity.
\end{abstract}

Keywords: ecclesiastical power, political power, biopower, State, christianity.

Articulo: Recibido el 20 de julio de 2021 y aprobado el 25 de octubre de 2021

\section{Cómo citar este artículo:}

Hernández Gamboa, R. (2021). El Estado absolutista y la reforma protestante como el umbral de la biopolítica. Reflexión política 23(48), pp. 111-123. doi: https://doi.org/10.29375/01240781.4210

\section{Introducción}

La administración y gestión de la vida biológica de los individuos por parte del Estado moderno es una característica intrínseca a su función de proteger y optimizar la existencia de los hombres para adecuarla a las diferentes relaciones de dominación. Esta función del poder soberano viabiliza la vida de los individuos al hacerla funcional a los diferentes dispositivos tendientes a su administración y uso, pero, al mismo tiempo, esta existencia humana optimizada protege, sostiene y posibilita la existencia del poder soberano al integrarlo y nutrirlo. Estos elementos representan los que Foucault (2014) llamaría biopolítica, es decir, la antesala a una regulación y control estable y permanente sobre la corporalidad, la razón y la comunidad de los hombres para asegurar con ello su supervivencia y evitar los conflictos que conlleven a su desaparición. La biopolítica, señala Foucault (2014), dispondrá sobre la vida y la 
muerte de los hombres, pero no sólo decidiendo si viven o si mueren, sino principalmente desarrollando una intervención en los procesos orgánicos de los individuos para su disciplinamiento, su regulación comunitaria y la conducción de su entendimiento y conciencia, fundando un paradigma de dominación que primará en la modernidad.

El control sobre la vida biológica de los individuos desarrollado por el poder soberano a partir del siglo XVII se contrasta con lo acontecido en las sociedades políticas del medievo. La gestión de la vida biológica durante esta época era potestad del poder eclesiástico que administraba la corporalidad, la conciencia y la comunidad de los sujetos para su control por parte de los prelados religiosos condicionada por el objetivo de alcanzar la vida eterna. El pastor cristiano se ocupaba de su rebaño en la medida que desarrollaba una intervención cotidiana e indeleble sobre su comportamiento y conciencia, pero también sobre los bienes y la riqueza de su rebaño (Foucault, 2014). La obediencia de las ovejas a su pastor era integral, siendo preciso que las enseñanzas abarcarán cada instante de manera más o menos discontinua para reconocer el comportamiento general de los individuos por medio de la observación, la vigilancia y la dirección. Los mecanismos de obediencia pastoral no se circunscriben sólo a la conducta sino sobre todo a la conciencia que se encontraba en constante examen como un instrumento de dependencia para reconocerse en el camino de la salvación eterna (Foucault, 2014). De este modo, el poder eclesiástico intervenía en la existencia orgánica de los individuos a través de una supervisión y conducción de su vida, estableciendo las simientes para la gestión del bíos como un instrumento de poder.

Este artículo se coloca en el ínterin del traspaso de responsabilidades sobre la gestión de la vida biológica de los individuos entre el poder eclesiástico y el poder soberano, entre el poder pastoral y la biopolítica. El objetivo de este texto es analizar los elementos que permitieron el desarrollo de las primeras practicas biopolíticas por los Estados modernos como derivación de la decadencia del poder eclesiástico, por lo tanto, en un primer momento este artículo abordará las implicaciones del Estado absolutista como respuesta a las intenciones de desapegarse de la autoridad de los prelados en los reinos europeos. Posteriormente, se describirá el debilitamiento del poder eclesiástico y la fortaleza de los soberanos que acompañaron el cisma de la curia romana en Europa, el cual se traducirá en la reforma protestante que impulsaría a la administración del bíos por el soberano. Finalmente, se analizará la novedosa autoridad de los soberanos para conducir y gobernar la vida biológica de sus súbditos en la modernidad como consecuencia de la deslegitimización del poder eclesiástico.

\section{El Estado absolutista}

El poder político durante la Alta y la Plena Edad Media se legitimó a través de dos mecanismos. El primero de ellos fue mediante la fuerza y la violencia propiciada por la introducción de las tribus bárbaras en las provincias romanas, lo que permitió la generación de reyes-guerreros que comandaban a sus ejércitos para apoderarse de tierras y de poblaciones a las cuales gobernar con total potestad derivado de su derecho de conquista (Rodríguez, G., \& Rigueiro, J., 2015). Este escenario supuso que los recambios en las élites del poder público se desarrollaran de forma violenta, por lo que la fuerza empleada en la desposesión de los reinos legitimaba los derechos del soberano. La segunda forma de legitimación del poder político durante este periodo fue a través del derecho divino afirmando los poderes dinásticos de los monarcas germánicos, encontrando a través del apoyo de la autoridad clerical la forma de sostenerse en el poder político por mayor tiempo y con relativa mayor tranquilidad (Mir, L. B., \& Dalcero, I., 2007).

Estas dos formas de legitimación política fueron las recurrentes hasta los siglos XIII y XIV de nuestra era, cuando los reyes anhelaron desembarazarse del poder clerical que los certificaba como autoridad terrenal (Espitia Garzón, 2016). Los monarcas aspiraban a librarse de la autoridad del papa y de sus cortes sin regresar a los años de violencia e incertidumbre ocasionados por la legitimación del poder político a través del derecho de conquista, provocando inseguridades en la sucesión del reino y guerras civiles, vacilaciones que habían sido solucionadas a través de la herencia al primogénito del rey y su autentificación por los prelados religiosos. 
Los monarcas europeos encontraron en el derecho romano y en su estudio un elemento que los distanciaba tanto de la violencia promovida por el derecho de conquista como de la tutela que el papado les ofrecía mediante el derecho divino. ${ }^{1}$ Fue Felipe IV de Francia quien en su disputa con el papa Bonifacio VIII ordenó a que se hiciera una compilación del jurisconsulto romano Justiniano, el cual en sus escritos mostraba una novedosa forma de legitimar la autoridad del emperador sin estar sujeta a la religión ni a la fortaleza militar de sus legiones, pudiendo comandar sobre sus súbditos, sus provincias y sus ejércitos de forma pacífica y ordenada (Espitia Garzón, 2016). Esta legitimación del emperador planteada por Justiniano derivaba de una ordenanza a los hombres por ser él el primero de los magistrados del Imperio, que tiene dominio sobre los ciudadanos, buscando para ellos el bien común a través de la ley y la justicia (Schipani, 2016). El poder soberano, derivado de esta interpretación, reconsideró el origen de su legitimidad, ahora como resultado de la búsqueda del bien común de los integrantes de su reino, mostrándose conveniente esta forma de legitimación para la baja nobleza y para la incipiente burguesía que se agrupaba en las cortes reales. El monarca apoyado en el derecho romano se constituyó como una figura que representaba los intereses de la comunidad, incubando los orígenes de los sentimientos nacionales, protegiendo a sus súbditos de cualquier acechanza extranjera y fungiendo como la autoridad suprema para comandar sobre la existencia terrenal de sus poblaciones (Schipani, 2016).

La frase del jurisconsulto romano Ulpiano que aparece en el Digesto de Justiniano (1889), que también fue recopilado por órdenes del rey Felipe IV: "Princeps Legibus Solutus est,”(D, 1, 3, 31) esto es, "el príncipe no está sujeto a la ley", enmarcó un nuevo carácter en las monarquías medievales, no sólo porque se reconocía a la autoridad de la primera magistratura del reino y se justificaba la instauración del absolutismo político; sino principalmente porque el rey se apartaba de las leyes, particularmente del derecho divino al que estaba sometido derivado de la tutela del papado. Este cambio fue fundamental, pues resultaba sencillo acusar a los reyes de impiedad por parte de los obispos de Roma ante cualquier desacato o afectación a los intereses económicos del papado, acusando a los monarcas de herejía y excomulgándolos, obligándolos a retornar al patrocinio ofrecido por la iglesia. La separación del poder público de las leyes divinas a través del derecho romano se mostraba como un alejamiento del rey a las causas de la iglesia, recuperando el monarca la autoridad para gobernar a sus súbditos sólo por las leyes que él mismo legislara.

Las monarquías que lograron aprovechar el desapego de la curia a través del derecho romano -Inglaterra, Francia y el Sacro Imperio Romano Germánico, principalmente-comenzaron a construir alrededor del soberano instituciones públicas más robustas, sentando las bases para la instauración de monarquías absolutistas, generando capacidades para la defensa y la manutención de la corona sin la necesidad de depender de los señores feudales y del clero romano (Romero, 1998). Una de las primeras medidas que emplearon los reyes fue la creación de un ejército profesional para la defensa del reino y particularmente del rey. El poder soberano desdeñó la antigua caballería nobiliaria que dependía de los señores feudales, así como la leva de los vasallos, con el objetivo de apuntalar nuevas compañías militares profesionales, es decir, militares que dependieran únicamente de la paga del rey, con armamento más diverso que el empleado por los caballeros, como las ballestas, resultando más difíciles de contener porque no respetaban las reglas del combate leal empleado por la nobleza. Este recambio se observa particularmente en la Guerra de los Cien Años entre los reinos de Francia e Inglaterra (1337-1453), pues

1. El ejerçicio poder público de la curia romana que sujetaba las facultades de las monarquías hereditarias estuvo apuntalado principalmente en el control, disposición e interpretación del derecho divino, pues fue una herramienta fundamental para el control político del conjunto de las sociedades en el medievo. Su relevancia derivó en que sólo la corte papal tuvo la soberanía para interpretar y modificar las leyes que regían sobre el conjunto de las monarquías europeas, lo que les consintió gobernar sobre reyes y siervos. La consolidación del derecho divino quedó enmarcada en las bulas papales de Bonifacio VIII, las cuales trascenderían a otros pensadores, el más importante de ellos fue Santo Tomás de Aquino, teólogo y filósofo catolico del siglo XIII, quien conservó la idea de Bonifacio VIII y de continuación y ruptura con San Agustín de Hipona (2017), abordando la prevalencia del poder espiritual sobre el poder terrenal. En su texto Del reino (2003), Santo Tomás de Aquino además de analizar cuál es el sistema óptimo de gobierno en las comunidades cristianas del medievo, aborda los deberes y las competencias de los reyes, así como las razones de este gobierno, enfatizando que el origen y la finalidad del poder político sobre los hombres es la salvación prometida por Dios. Esta defensa de Santo Tomás de Aquino (2003) a la autoridad divina del papa sobre el poder terrenal de los reyes también exigió una nueva configuración en sus potestades, la cual se dibujo en la distinción entre el alma y el cuerpo y su vinculación con el poder terrenal y con el poder espiritual. Para el teólogo siciliano, el alma, lugar donde se aloja la virtud creación por Dios, tiene que ser gobernada por el poder espiritual, en cambio, el cuerpo regido y movido por el alma tiene que ser una potestad propia del rey. Concepcion diferente a la expresada por San Agustin de Hipona (2017) y por los textos teologicos del catolicismo, los cuales establecian al cuerpo como un elemento sagrado muestra de la divinidad de Dios, por ello su gobierno tenia que estar supeditado a las ordenanzas religiosas que buscaban atemperar los impulsos pasionales y administrar las necesidades organicas para asi lograr su salvacion y posterior resurrección. Este que buscaban establecer los poderes del monarca, justificando esta coalición en la defensa de la vida biológica de los hombres. 
la derrota de los franceses en un primer momento se debió a la parsimonia de los caballeros ante el asedio de Calais, y su victoria final ante el reino inglés derivó de la creación de un ejército constituido por los burgueses y los campesinos franceses que seguian únicamente órdenes del rey a través de seis divisiones que se establecieron como permanentes (Romero, 1998).

Otra medida importante para la instauración del absolutismo fue la creación de la burocracia real encargada de administrar los territorios y cobrar los impuestos entre la población. Esta burocracia formada por los cuadros laicos que egresaban de las universidades aspiraba a ocupar amplios poderes en el Estado y ascender jerárquicamente en la escala social, permitiendo que al monarca centralizara las potestades del Estado en su persona (Fueyo Álvarez, 1956). El poder de la monarquía absolutista a través de la burocracia real restructuró las relaciones de dominación al reformar las condiciones económicas en el reino, retirando las trabas comerciales impuestas por los señores feudales al mercantilismo, colocando nuevas normatividades de acuerdo con las necesidades de la corona, como monopolios únicamente aprovechables para el rey y liberalizando el territorio para comerciar sin más impuestos que los cobrados por la corona (Pounds, 1981).

La novedosa organización de las monarquías absolutistas generó nuevas identidades políticas desarrolladas no únicamente a través de la filiación local con el señor feudal, con las iconografías sacras administradas por el clero secular o con el universalismo promovido por la curia romana, sino ahora, estas identidades políticas se abordaban entorno al rey y a la promoción de los sentimientos nacionales. La guerra de los cien años fue un suceso fundamental que aseveró esta transformación. Tanto ingleses como franceses utilizaron los sentimientos nacionales para reconocer su legitimidad sobre la sucesión de la corona francesa de Carlos IV y el intento por evitar que los reyes normandos que gobernaban Inglaterra, particularmente Eduardo III, pudieran acceder a ella, unificando sus posesiones en un solo reino y convirtiendo a los franceses en vasallos de la corona inglesa, a pesar de que las leyes de sucesión de la corona francesa así lo confirmaban.
El nacionalismo fundado en la soberanía del rey se engarzó con el control progresivo sobre el territorio y la población a través de la burocracia real, del nuevo sistema de impuestos, de la promulgación de legislaciones que sancionaban ciertas conductas públicas y de la regulación sobre las relaciones económicas (Anderson, 1993). La autoridad terrenal del rey comenzó a ser radicalmente mayor que en los siglos anteriores, ocupándose en mayor medida de la vida biológica de los individuos para que la iglesia se dedicara más en guiar la existencia espiritual de los hombres (Santo Tomas de Aquino, 2003). Este control del poder político sobre la vida biológica de los individuos tardaría mucho en afirmarse; no obstante, la Iglesia católica batallaría para evitar que sus influencias sobre la razón, la corporalidad y la comunidad de su rebaño desfalleciera por la autoridad del monarca.

\section{El debilitamiento del poder eclesiástico}

Las fracturas en la Iglesia católica que permitieron que los reyes agruparan potestades en torno a la gestión del bíos iniciaron en el siglo XI con el advenimiento del Cisma de Oriente (Mitre Fernández, 1986), ${ }^{2}$ no obstante, la vacilación capital de los poderes eclesiásticos sucedió en el siglo XIV en el enfrentamiento entre el absolutismo monárquico impulsado por el rey Felipe IV de Francia y la doctrina teocrática de Bonifacio VIII, excomulgando el papa al rey y este secuestrando al Papa, lo que determinaría la muerte del pontífice (Bayona Aznar, 2016). Después de la muerte de Bonifacio VIII el papa fue designado con el beneplácito del rey de Francia que tenía fuerte influencia en la nobleza romana y en los cardenales electores, siendo elegido el arzobispo de Burdeos como Clemente $\mathrm{V}$ quien fue coronado en Lyon y fijó su residencia en Aviñón, iniciando una dinastía de Papas asentados en esta localidad que reflejarían su dependencia del poder terrenal (Galland, 1998).

Para entonces la cristiandad estaba extraviada entrelos Papas franceses que respondíanalos intereses de la corona y olvidaban la sacralidad de la Ciudad Eterna y la gran cantidad de recursos económicos que se acumulaban en Aviñón, patentizando el objetivo de cierta parte del clero del acopio de riquezas y de placeres terrenales, rechazando la retracción de

2. El papa León IX y el patriarca de Constantinopla Miguel I Cerulario, se excomulgaron mutuamente por ambos anhelar la autoridad suprema sobre la cristiandad, cercenando para Roma todos los territorios del Imperio bizantino y de los reinos eslavos que se adhirieron al poder ecuménico del patriarca de Constantinopla (Petrucci, 1977). 
las pasiones como mandataba el evangelio (Sánchez, 199). Las atribuciones de los prelados titubeaban junto con su legitimación para conducir la vida de su rebaño. La constricción de las pasiones, los deseos y los intereses personales que aseguraban una vida superior no eran respetados ni por los promotores del reino de los cielos. ${ }^{3}$

Esta desorientación del cristianismo se acrecentaría con el Cisma de Occidente en los siglos XIV y XV, en donde numerosos prelados se disputarian la autoridad Papal para hacerse de sus potestades y riquezas. ${ }^{4}$ En el año 1415 se instituyó un interregno dentro de la iglesia que sería comandado por un concilio que se establecería en la ciudad de Constanza, desconociendo la autoridad de los diferentes papas y antipapas. Este concilio designaría al poco tiempo a un nuevo obispo de Roma nombrado Martín V que, buscando conciliación, intentó reformar a la Iglesia romana al buscar erradicar la corrupción entre los integrantes del clero, manteniendo la retracción de los placeres terrenales que los distinguían como virtuosos entre su rebaño. Sin embargo, sus trasformaciones no serían tan sustanciales para erradicar estas disputas que se actualizarían en el siglo XVI (Bayona Aznar y de C. R. de Souza, 2013). El nombramiento de Martín V sólo disimularía el afianzamiento del poder terrenal sobre el poder espiritual que se atrevía a manifestar su independencia.

En los siglos XV y XVI se generó un pensamiento político que se apartaba de la vertiente religiosa que hasta entonces había explicado la autoridad del poder soberano, acercándose a un nuevo paradigma que pasaba por vislumbrar los elementos humanos que lo conformaban. Este cambio en el pensamiento político buscó desentrañar el origen del poder soberano y los medios para mantenerse en él, ya que, debido a la caída del poder eclesiástico, el derecho divino no alcanzaba para explicar la naturaleza del poder terrenal sobre los individuos. Así lo entendió Nicolás Maquiavelo (1469-1527), quien en su texto El príncipe (1998) intentó explicar de manera descarnada cómo es que los soberanos obtenian este predominio sobre los hombres y de qué forma debían de conservarlo, ubicando en ello una forma de legitimación política desapegada de los designios divinos y de los derechos de conquista que habían primado en el medievo. ${ }^{5}$ Las reflexiones de Maquiavelo en El príncipe giraban en torno al comportamiento del soberano para mantenerse en el poder político, estableciendo las medidas de riqueza, fuerza y benevolencia que debían de administrarse hacia sus súbditos para evitar su derrocamiento y salvaguardar su autoridad, así como para identificar las problemáticas del reino, impidiendo que se convirtieran en situaciones que desafiaran su predominio.

Las reflexiones de Maquiavelo fueron revolucionarias; alejadas de las voluntades divinas y por ende virtuosas de los hombres, el florentino se centró en las pasiones y en las necesidades de los individuos a los que calificó como perversos y rapaces en la lucha por hacer realidad sus deseos. Guiados por las satisfacciones momentáneas, los hombres muestran su parte bestial y su parte humana de acuerdo con sus intereses. La advertencia que Maquiavelo hace a los soberanos sobre el

3. El papado no sólo significaba la dirección espiritual de los hombres, sino principalmente representaba el control sobre las riquezas que sus posesiones y sus potestades generaban, como fueron los feudos ecleșiásticos, los censos pagados al papa por los Estados pontificios, los tributos recaudados por las abadías y los conventos que derivado de las inmunidades papales eran recolectados por el clero, los tributos pagados por los reinos vasallos de Roma y una serie de favores espirituales e inmunidades papales que eran vendidos para recibir el permiso o el perdón de la iglesia, llamando a esta actividad simonía (Galland,1998). El provecho económico obtenido por el papa y sus allegados hacían de este cargo un anhelo tentador para los obispos, por lo que los pontífices romanos preferían aliarse al poder regio antes que abandonar su posiciones eclesiástica, aceptando arreglos contrarios a los intereses del cristianismo como la disolución de la orden militar de la Temple que había reunido cuantiosas riquezas en las cruzadas y que Clemente V aceptó disolver en beneficio de Felipe IV, quien confisco todas las posesiones de la orden en Francia (Mezzadri, 2001). La curia romana se convirtió no sólo en la dirigencia de la lglesia católica intervenida por la monarquía francesa, sino principalmente en una serie de instituciones eclesiásticas conducidas por una elite clerical corrompida por la búsqueda de placeres terrenales y posesiones materiales, por lo que nopocas voces dento de la iglesia empezaron a discernir de este comportamien que los mantenia dependientes del poder terrenal y de las

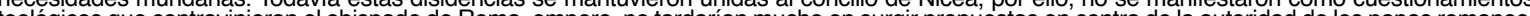

4. le lo lcos que contrin

A la muerte de Gregorio XI, tanto la curia pontificia de Avinón como los cardenales residentes de Roma, designaron a su propio papa, el romano

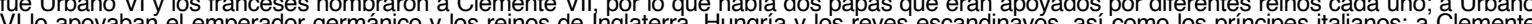
Vilo apoyaban el emperador germánico y los reinos de inglaterra, Hungria y los reyes escandinavos, asi como los príncipes italianos; a Clemente Villo lescol, 140 . (

. existieron al mismo tiempo tres papas distinos que se autoproclamaban dirigentes de la cristiandad en

5. El contexto de las ciudades italianas en las que escribió Maquiavelo no estaba alejado de la decadencia de los señoríos feudales, del ocaso del poder eclesiástico y de la relevancia del poder absoluto de los monarcas y de las instituciones estales que los arropaban, así como de una incipiente enriquecerse. Las ciudades-Estado de Milan, Florencia, Venecia, Génova y Nápoles en la península itálica, que desde el siglo XII se habia desembarazado de la autoridad imperial del Sacro Imperio Romano Germánico al apoyar la postura del papa en la Querella de las Investiduras, eran del deseo de los grandes reinos europeos que se disputaban su predominio a traves de alianzas militares y políticas que desmembraban la unidad de los principados italianos en connivencia con los obispos de Roma. Estas ciudades eran gobernadas por familias acaudaladas, dependientes o en mancomunidad con las coronas europeas, las cuales aprovechaban su posicion para capitanear el comercio entre los reinos occidentales y las ciudades del adriatico, siendo un vínculo comercial de la tierra esquivando la autoridad de los señores feudales y mejorando con ello las cosechas de los fértiles territorios italianos, lo que conllevó al de la tierra esquivando la autoridad de los señores feudales y mejorando con ello las cosechas de los fertiles territorios italianos, lo que conllevó al aumento de la poblacion y al desarrollo de las artes, convirtiendose en comunidades ricas, educadas y dispuestas a la guerra en contra de sus vecinos y equilibrar los diferentes intereses internos y externos para conservarse en el principado. 
comportamiento "natural" de los hombres, conlleva a que estos no vacilen en utilizar la fuerza ni los engaños para controlar a los súbditos (Maquiavelo, 1998, pp. 112-114). Si el príncipe pretende guiarse por el comportamiento que certifica a los hombres cristianos como la fe, la caridad, la paz, la lealtad y la religión, perderá su reino ante la avaricia de los hombres y su búsqueda por satisfacer sus deseos a cualquier precio. Los príncipes deberán evitar estas benevolencias y ser severos en su gobierno, pero también deberán cuidarse de aparentar tales comportamientos si desean mantener su dominación (Maquiavelo, 1998, pp. 114-115). El príncipe para conservar su poder deberá hacerse temer por sus súbditos antes que hacerse amar por los mismos. El amor es un sentimiento de gratitud que se rompe si los hombres se benefician de ello, en cambio el temor es un sentimiento que inspirará miedo al castigo provocado por su desafección, de manera que será la violencia necesaria la forma de hacerse obedecer por sus súbditos sin dejar de lado la dosis de clemencia que afirmará esta dominación para evitar convertirse en despotismo (Maquiavelo, 1998, pp, 112).

La interpretación que Maquiavelo hace del poder político transforma las implicaciones que había propuesto la escolástica cristiana sobre la actuación de los soberanos. Para la exégesis cristiana, el poder soberano debía administrar los reinos en comunión con el poder eclesiástico, guiando las leyes terrenales y los territorios de su reino para la transición de la vida mundana a la vida celestial. Lo que propone Maquiavelo es colocar en un segundo plano la existencia supraterrenal para reconocer que en la existencia mundana, los placeres, las pasiones y las necesidades de la vida biológica determinan el comportamiento de los hombres y de los soberanos, por lo tanto, el príncipe no deberá de enfocarse en rehabilitar los comportamientos terrenales mediante el control espiritual como señalaba la escolástica, sino deberá de administrar los impulsos biológicos a través de la fuerza y la razón para que estos no amenacen su predominio.

Porque de los hombres cabe en general decir que son ingratos, volubles, falsos, cobardes y codiciosos; y que mientras los tratas bien son todo tuyos, te ofrecen su sangre, sus bienes, su vida y sus hijos, como antes dije, más siempre y cuando no los necesites; pero cuando es así, se dan media vuelta [...] Y se ha de tener presente lo siguiente: que un príncipe, máxime si se trata de un príncipe nuevo, no puede observar todas aquellas cualidades por las que se reputa a los hombres ele buenos, pues con frecuencia se requiere, para mantener el Estado, obrar contra la lealtad, contra la compasión, contra la humanidad, contra la religión. Por ello necesita tener un ánimo dispuesto a girar a tenor del viento y de las mutaciones de la fortuna, y, como dije antes, a no alejarse del bien, si puede, pero a saber entrar en el mal, de necesitarlo. Debe, por tanto, un príncipe preocuparse porque nunca salga de su boca nada que no destile las antedichas cinco cualidades, y parezca, cuando se le ve o se le oye, toda clemencia, toda lealtad, toda integridad, toda religión. Siendo esta última la que más de todas debe aparentar tener, pues los hombres, en general, juzgan más con los ojos que con las manos, pues ver es de todos, mientras que tocar es de pocos. (Maquiavelo, 1998, pp. 112, 114-115).

Maquiavelo mantuvo la perspectiva cristiana del hombre perverso y avaricioso que sólo mira por su satisfacción biológica e individual, pero se transforman los medios para tratarlos. Del control sobre la corporalidad, la conciencia y la comunidad a través de un mensaje divino que es menester de los clérigos transmitir y con ello transformar las actuaciones pecaminosas de los hombres encaminándolos hacia su salvación, se transfigurará hacia la fuerza y la violencia por parte del soberano para refrenar estos impulsos egoístas y avariciosos con la finalidad, no de conducir su existencia biológica hacia una vida superior o supraterrenal, sino de constreñir tales arrastres para impedir que estos impulsos resistan al poder de los príncipes o le disputen su autoridad. Lo que propone Maquiavelo es olvidarse de las potestades divinas que miraban el reino de los cielos, mostrando descarnadamente las condiciones del mundo terrenal y las posibilidades que tenían los príncipes para gobernar sobre las poblaciones, determinando en cierta medida su comportamiento y su razón (Marasco, 2012). Con ello, Maquiavelo no clarifica las potestades del soberano para gestionar la vida biológica de los individuos a través de las instituciones, leyes o dispositivos del Estado, pero sí muestra que tal administración de las poblaciones podrá desarrollarse a través de la violencia ejecutada por el soberano sin depender de la voluntad divina o de los mandamientos religiosos. 
El soslayar las posibilidades del clero católico deintervenir en el poder político que enuncia, o más bien, obvia Maquiavelo, es la consecuencia de la descomposición de las instituciones eclesiásticas a pesar de la resolución del cisma de occidente. La avaricia, la corrupción y la ignorancia de los integrantes del obispado de Roma crecían a la par que lo hacían los poderes de las monarquías absolutistas. La venta de puestos dentro de la iglesia que les aseguraban a los hombres empleo fijo bien pagado y el comercio de indulgencias que libraban a los individuos del pecado se convirtieron en un círculo vicioso que aumentó el tamaño de la curia papal y también los recursos que necesitaban para su manutención, obligando a los obispos a recurrir a diferentes formas de financiamiento para asegurar su viabilidad. Esto evidentemente distrajo a los Papas de sus ordenanzas religiosas, centrándose menos en alcanzar una vida virtuosa en el reino de los cielos y más en los alcances de la vida terrenal a través de la satisfacción de sus necesidades y placeres.

Tal situación fue advertida por Erasmo de Rotterdam (1466-1536), quien fue sacerdote y teólogo del cristianismo. Erasmo dedicó a este escenario los comentarios de su publicación en latín de los Evangelios:

Como en tiempos de San Pablo, había pocos sacerdotes, el apóstol no prohibió que se casaran ni obispos ni clérigos ni diáconos. Pero ahora se prohíbe el casamiento de los ordenados y se les permiten homicidios parricidios, incestos, piraterías y sacrilegios. En innumerables rebaños de clérigos, pocos son castos [...]. (Mateu, 2007, p. 124)

Evidentemente, la crítica de Erasmo no pasó inadvertida para el clero romano, intentando excomulgarlo y evitando que sus textos se leyeran en las universidades, pero las denuncias del pensador neerlandés se olvidaron derivado de un desafío mayor, ya que no sólo criticaba las acciones de los obispos, papas o cardenales, sino que intentaba romper con el predominio del obispado de Roma en occidente.

\section{La reforma protestante}

Fue Martín Lutero (1483-1546) quien encabezó un movimiento que cismaría a toda la cristiandad por sus denuncias a los privilegios de la nobleza papal. Lutero, de familia humilde, dedicó los primeros años de su vida a un comportamiento monástico hasta que, en el año 1507, fue ordenado sacerdote, y en el año 1508 comenzó a enseñar teología en la Universidad de Wittenberg, lugar desde donde cuestionaría el poder de las instituciones del catolicismo y sería su refugio de las inventivas de sus opositores. Sus principales críticas al catolicismo se publicaron en sus 95 Tesis (2017) que giraban en torno a la decadencia moral de los clérigos que habían transformado a Roma en una ciudad enviciada, convirtiendo a la iglesia en un negocio más a las órdenes del papa. Estas primeras diatribas pronto se le añadirían cuestionamientos a la organización de los cultos cristianos, a los misterios ofrecidos por la iglesia y a la intermediación de la jerarquía religiosa entre los hombres y el evangelio.

Las disputas teológicas fueron ríspidas, viéndose obligado Lutero a esclarecer sus proposiciones en tres textos que se publicarían en el año de 1520: De la Libertad cristiana (2016), La cautividad babilónica de la Iglesia (2018) y Manifiesto a la nobleza cristiana de la nación alemana (2017). Este último texto es particularmente interesante, no sólo porque llama anticristo al papa, sino porque sistematiza una serie de demandas doctrinales y sobre la organización de la Iglesia cristiana, tales como la revocación de los ingresos del papa, la supresión del enorme número de días santos, la disminución del número de cardenales, el reconocimiento del gobierno secular, la anulación del celibato del clero, la abolición de los interdictos, la derogación del peregrinaje, la eliminación de los conventos del clero regular, una reforma en las universidades para limitar la influencia del papado y una transformación radical de la moral cristiana. Este texto también contiene un llamado a toda la nación alemana para que se una en contra de los excesos romanos. Si el papa, dice Lutero, les había entregado a los alemanes el título del Imperio romano, pero se había quedado con todo el poder, las riquezas, el cuerpo y el alma de sus pobladores, es ahora el momento en el que a través de este mismo título imperial los alemanes le arrebaten todas las potestades dadas al papa, regresándolas al emperador

Si hacen alarde de habernos entregado un Imperio, bien, ¡que así sea! Administrémoslo, y que el Papa entregue a Roma y cuanto tiene del Imperio, que 
deje libre nuestro país de sus intolerables tributos y extorsiones; que nos devuelva la libertad, el poder, la fortuna, la honra, el cuerpo y el alma, y que deje existir el Imperio como a este corresponde, cumpliendo con sus palabras y afirmaciones. (Lutero, 2017, p. 40).

Tal enunciación de Lutero es fundamental para entender el traspaso de la gestión de la vida biológica del poder eclesiástico al poder secular. En esteapartadono sólo semanifiestan las posibilidades de los soberanos de gestionar las pasiones de los individuos a través de la violencia como lo proponía Maquiavelo, sino esclarece Lutero que la existencia biológica de los hombres únicamente les es propicia a los reyes, emperadores o príncipes, es decir, al poder soberano. En insinuaciones de Lutero, el rey es el único facultado para intervenir en el cuerpo, en el alma y en la libertad de los hombres para conducirlos por los senderos del cristianismo.

La inclinación de Lutero hacia la gestión del bíos por parte del poder secular está en concordancia con el cuestionamiento que se encuentra en La cautividad babilónica de la Iglesia (2018), en donde el autor cuestiona al misterio católico defendido desde el cristianismo primitivo de la transustanciación del cuerpo y la sangre de Cristo en la eucaristía, el cual sacraliza la vida biológica de los hombres, disponiéndolo para su administración como un elemento sacro y propicio para su control por parte de los prelados religiosos. Lutero rechaza tanto la sacralidad de esta vida a través de la eucaristía como la gestión del bíos por parte de las instituciones clericales, permitiendo que el poder secular intervenga para beneficio de los hombres. Lutero afirma que la autoridad de los monarcas seculares es dada por Dios, los cuales se distinguen por castigar a los hombres malos y proteger a los hombres buenos, por ello es menester que estos monarcas guíen la corporalidad y el alma de los individuos, obteniendo estas potestades para la salvaguardia de todo el cristianismo, aun y por encima de la jerarquía eclesiástica. El poder secular tiene que intervenir libremente y sin estorbos en los miembros del cuerpo entero del cristianismo, procediendo a castigarlos cuando así lo merezcan. A través de las leyes humanas y cristianas el príncipe podrá discernir el comportamiento de los individuos y será él quien defienda la naturaleza orgánica de los hombres (p.3-6).
La muralla, como califica el reformador cristiano a la jerarquía católica, tiene que ser derribada por el cuerpo de cristo en el que se agrupan todos los individuos, pero en el cual sobresale una cabeza que es entregada por Dios a los hombres, siendo el poder secular la cabeza que tiene que guiar esta lucha en favor del cristianismo para destruir los privilegios con los que se ha mantenido la curia papal. El soberano será el encargado de reconstruir al cristianismo. Así como sucedió en el pasado en donde el emperador romano fue el único facultado para convocar a un concilio, ahora los reyes, príncipes y emperadores deberán convocar a reuniones de toda la cristiandad para alejarse de los vicios y privilegios de la nobleza papal (Lutero, 2018, p. 8-9). El soberano deberá prevalecer por encima del poder eclesiástico, condenar a los integrantes "pervertidos" del clero que se han beneficiado de sus funciones y defender a los inocentes de las injusticias ocasionadas. El poder político deberá de encargarse en todo lo concerniente a los bienes, la razón y la corporalidad de los cristianos, es decir a la vida biológica, evitando que tales elementos sean adheridos al poder eclesiástico los cuales únicamente deberán tratar los temas de la fe y de las buenas costumbres, es decir, de la vida eterna, para lograr entrar al reino de Dios y alcanzar una existencia superior (Lutero, 2018, p. 17).

Por esto, cuando la necesidad lo exija y el Papa resulte escandaloso para la cristiandad, ha de colaborar quien mejor pueda, como miembro fiel de todo el cuerpo, para que se realice un verdadero concilio libre. Nadie puede hacer eso tan bien como la espada secular, sobre todo porque ahora son también cristianos, sacerdotes, eclesiásticos y competentes en todas las cosas. (Lutero, 2018, p.8)

La transformación que propone Lutero parte de entregarle al poder soberano la gestión sobre la existencia biológica de los hombres, así como la administración sobre los bienes terrenales y la corporalidad de los individuos, participando en la justicia, la salud y la educación de los hombres, incluido la regulación del matrimonio (Lutero, 2018, p. 42). El luteranismo dará las herramientas a los Estados, no sólo para regular las pasiones de los hombres a través de la violencia como lo exponía Maquiavelo, sino para hacer de este campo de las pasiones, las necesidades, los intereses y las satisfacciones mundanas un terreno exclusivo 
del poder soberano en donde fundamentarán su autoridad.

\section{El umbral de la biopolítica}

Los soberanos electores del Imperio Germánico se aprestarían a defender la reforma luterana, que más que desafiar el poder del papado romano con otra institución religiosa análoga, lo que hacía era desafiar la autoridad política del clero católico. Los soberanos observaban en esta revolución una nueva configuración en las relaciones de dominación que permitían que sus facultades se acrecentaran a costa del poder eclesiástico, ya sea porque reconocían la importancia de la gestión de la vida para su autoridad política, o ya sea porque de manera más evidente se beneficiaban del arrebato a las propiedades episcopales en sus territorios. El emperador Carlos $\mathrm{V}$ intentó mediar esta confrontación al interior de la iglesia, rehaciendo el papel del emperador Constantino en el desafío de la herejía arriana mil años atrás, pero la diferencia estribaba en que esta confrontación se alejaba de las concepciones teológicas trinitarias y se acercaba a la materialidad de las relaciones de dominación dentro del Imperio. Los príncipes germánicos veían en la reforma más una transformación del poder político que una revolución de las concepciones místicas.

Carlos V exigió la unidad religiosa de sus subordinados, pero los príncipes alemanes reclamaban el proceder libremente en sus dominios. El rey, intentando reconstruir el cristianismo alrededor de su persona, convocó a varias dietas imperiales. En estas se afirmaron diversos postulados religiosos, pero sobre todo políticos. El acuerdo que resultó crucial para el cristianismo en los principados germánicos provino de la segunda dieta de Augsburgo en el año 1548, en donde el emperador impuso un interim entre católicos y protestantes, es decir, un decreto imperial llamado "Declaración de su Romana e Imperial Majestad sobre la observancia de la religión dentro del Sacro Imperio hasta la decisión del Concilio General”, en el cual el emperador buscó gobernar temporalmente al cristianismo en sus dominios a la espera del concilio religioso.

Carlos V elaboró una serie de modificaciones en los cánones del catolicismo, así como en las reformas implementadas por el luteranismo, restaurando para todo el Imperio el número de sacramentos que los luteranos habian reducido a dos, rehabilitando las doctrinas y las prácticas tradicionales del catolicismo, aprobando la transubstanciación del cuerpo y la sangre de cristo en la eucaristía, permitiendo el matrimonio de los clérigos religiosos y eximiendo la interpretación religiosa en relación a la salvación por medio de la fe y no de las obras como lo señalaban los luteranos. Estos cambios fueron parte de un proceso en el cual el poder soberano se apoderó de los elementos que el poder eclesiástico había conservado durante todo el medievo, es decir, de la gestión de la vida biológica de los individuos. A través del control sobre la teología cristiana, las leyes religiosas, los sacramentos místicos y la designación de los prelados, el emperador exteriorizó su control sobre la corporalidad, la razón y la comunidad de los individuos para gestionar su comportamiento. La nueva potestad del emperador preocupó a los católicos y al papa de Roma, los cuales observaban cómo el emperador germánico tomaba una influencia en los hombres que superaba a la de los antiguos emperadores romanos (MacDonald, 1992). Ahora, el poder soberano podía determinar la conducta y el pensamiento de los individuos a través de una religión que estaba esencialmente afirmada en gobernar el bíos de los individuos.

Las resoluciones del interim de Carlos V no complacieron ni a los católicos que observaban las implicaciones del poder político en el poder espiritual, ni a los protestantes, particularmente a los integrantes de la Liga Esmalcalda que reunían a los príncipes protestantes del Imperio, pues notaban cómo la autoridad sobre los hombres recaía en el emperador y no en los príncipes que dirigian esta cruzada. La disputa ya no se centró tanto en los elementos teológicos que distanciaban a los católicos y a los protestantes, estos se habían resuelto desde la primera dieta de Augsburgo, se concentró en quien controlaría los elementos que afirmarían y gestionarían el bíos de los individuos; el clero, el emperador o los príncipes electores del Imperio. Las distintas facciones se enfrentaron en refriegas menores que intentaron sosegarse con el decreto imperial conocido como interim de Leipzig, en el cual se permitió que los protestantes conservaran el núcleo de sus creencias religiosas, particularmente en relación con la salvación por medio de la fe, en cambio, se respetarían las propiedades de la Iglesia católica que todavía no habían sido ocupadas por los luteranos. Esta 
propuesta fue rechazada por los gnesioluteranos debido al temor "a que vengan los romanos" de nueva cuenta a ocupar los espacios controlados por la nueva fe. Para estos reformistas lo que estaba en juego era la ocupación de las potestades que hasta entonces habían pertenecido a la jerarquía católica y que ahora ellos ocupaban apuntalados por su cercanía al poder secular de los príncipes electores del Imperio (Svensson, 2019).

La pacificación del imperio se logró con la tercera dieta de Augsburgo, en la cual se firmó la paz religiosa que concedió a los príncipes germánicos la capacidad de elegir la confesión que ellos quisieran para sus reinos, practicándola en sus Estados con total libertad, arrastrando a sus súbditos en el credo religioso del soberano $\mathrm{u}$ obligando a estos a emigrar de sus territorios si es que se negaban a practicar su fe (cuius regio, eius religió). Esto evidencia la autoridad que ocupó el poder soberano para comandar sobre sus pobladores, decidiendo sobre su doctrina religiosa, sobre el comportamiento derivado de esta doctrina y sobre la posibilidad de integrarse o no a la comunidad creyente del soberano, estableciéndose de manera clara el vínculo entre el poder político y la gestión de la vida, dando el primer paso hacia la administración biopolítica de los hombres, es decir, hacia al control y gestión estable y permanente sobre la corporalidad, la razón y la comunidad de los hombres desde las instituciones del poder político.

Las diferencias religiosas que se zanjaron temporalmente en el Imperio germánico coexistieron en el reino francés, en donde la vertiente protestante calvinista más radical que la luterana había influido en los franceses del norte del reino y en la antigua nobleza feudal luchando por consagrar un nuevo cristianismo. El absolutismo de la corona francesa más consolidado que el del Imperio germánico evitó que los gobernantes de las diferentes provincias tuvieran el mismo poder que el de los príncipes electores del Imperio, por ello las regiones enteras que se mudaron al protestantismo en Alemania no se observaron en el reino francés. De igual forma, la radicalidad del calvinismo ginebrino en cuestiones sacramentales, en el juicio sobre los pecados y en las interpretaciones teológicas, inhibieron a pasarse del lado protestante. Buena parte de los convertidos al protestantismo en Francia pasaban más bien por su acercamiento a la antigua nobleza feudal que había perdido sus derechos por el establecimiento del absolutismo, que a las hordas de campesinos germánicos que apoyaban a los reformistas en el Imperio.

Las batallas que se libraron durante el siglo XVI ilustran los constantes encuentros y desencuentros entre los confesionales religiosos, los cuales intentaron ser mediados por la corona francesa para pacificar y unificar el reino. Sin embargo, también el trono estaba en disputa entre las familias nobiliarias que defendían una $\mathrm{u}$ otra religión, por lo que no se lograría la pacificación del reino hasta la promulgación del Edicto de Nantes en el año 1598 por el rey borbón y calvinista Enrique III.

El edicto de Nantes, así como la tercera dieta de Augsburgo, son una muestra de cómo los Estados europeos evolucionarían en sus funciones entorno a la gestión de la vida biológica de los individuos desde el poder político. La paz de Augsburgo decretada por el emperador obligó a que los individuos declararan públicamente su religión ante una instancia estatal, para, de esta manera, el Estado determinar si estaban en concordancia con las del soberano alemán, así como los luteranos tenian que entregar al Imperio los bienes y las tierras secularizadas a la iglesia antes del año 1552. El Edicto de Nantes, por otro lado, obligó a los individuos a olvidar las batallas religiosas entre los años 1585 y 1598, dándoles seguridad personal a los calvinistas, así como determinando dónde es posible practicar qué religión y cuál instrucción religiosa se tenía que enseñar a los jóvenes. El Estado utilizó a la religión como un instrumento a través del cual podía administrar el pensamiento, el comportamiento, las pasiones y las riquezas de sus súbditos, cambiando el espectro de la gestión del bíos del ámbito privado clerical al ámbito público y, por lo tanto, político.

Esta situación se modelaría más claramente en el reino inglés en donde la cuestión real en la anulación del matrimonio entre Enrique VIII de Inglaterra y Catalina de Aragón en el año 1526 por la ausencia de un heredero varón supuso un desafío para el papa romano. El papa Clemente VII se encontraba subordinado a las órdenes del emperador germánico Carlos V, quien era sobrino de Catalina de Aragón, complicando el deseo del rey inglés de separarse de su consorte española. Derivado de ello, el rey modificó su relación con el papa, mudando la posición de los prelados religiosos y secretarios del reino, imponiendo a los favorables a la causa del rey como Thomas 
Cromwell quien siendo primer ministro suprimió el Óbolo de San Pedro, trasladó las legislaciones eclesiásticas a las potestades del soberano y aprobó el divorcio en Inglaterra sin la necesidad de la intervención papal, o Thomas Cranmer, quien siendo arzobispo de Canterbury aprobó el divorcio entre Enrique y Catalina, avaló la sustitución gradual de los clérigos obedientes a Roma y ofició el casamiento del rey con Ana Bolena, ungiéndola como legitima reina de Inglaterra.

El papa respondió excomulgando al rey inglés, pero la separación entre la corona inglesa y la curia romana ya estaba encauzada. Tan pronto como pudo, el parlamento dirigido por Cromwell aprobó leyes en las cuales Inglaterra se desembarazaba de la tutela papal. Entre estos cambios estuvieron el estatuto de restricción de apelaciones que canceló la posibilidad de las reclamaciones eclesiásticas al papa, también se aprobó la Ley de las designaciones eclesiásticas en la cual todos los clérigos tenían que ser elegidos por el soberano, de igual forma se decretó la Ley de traiciones, la cual castigaba con la muerte el desconocimiento de la autoridad suprema del rey en la tierra, y por último, la Ley de supremacía en la cual se declaró que el rey era la única cabeza suprema de la iglesia en Inglaterra. El control sobre el comportamiento y el pensamiento religioso llevó a la corona a instituir el cargo de regente espiritual a cargo de Cromwell, quien supervisó las acciones de los conventos y monasterios religiosos, haciéndose de sus riquezas y bienes en favor de la corona inglesa.

Después de múltiples enfrentamientos entre los reformistas y los católicos en 1559, Isabel I aprobó el Acta de Uniformidad, que al igual que el Edicto de Nantes o la Paz de Augsburgo, determinó las características del servicio religioso dentro de su soberanía, decretándose los elementos teológicos y sacramentales del cristianismo, modificando el libro de las plegarias, prohibiendo expresar su repudio a la curia romana, invalidando la transubstanciación del cuerpo de cristo en la eucaristía y estableciendo las sanciones a quienes desobedecieran las órdenes del soberano en materia religiosa, practicando públicamente otra religión a la reglamentada por la reina. Isabel I normó la prohibición del casamiento de los clérigos, el respeto por algunos sacramentos religiosos del catolicismo como la confesión y la instauración de una jerarquía eclesiástica similar a la católica. En total fueron treinta y nueve artículos religiosos regulados por el poder político en el que principalmente se refrendaban los cánones teológicos del protestantismo, dejando en la ambivalencia otros tantos que se afirmaban en el catolicismo romano. Estas transformaciones teológicas y políticas muestran cómo el soberano emprendió los pasos hacia una regulación sobre la vida de los súbditos a través del control sobre la doctrina religiosa, y con ello sobre el comportamiento y la conciencia de los individuos, comenzando por la administración de la educación, la reproducción, las pasiones y los deseos desde el ámbito público.

De la guerra religiosa entre católicos y protestantes y de la guerra civil inglesa entre realistas y parlamentarios provienen las fuentes que moldearon el pensamiento de Thomas Hobbes tendiente a la generación de una sociedad civil que pacte con el soberano absoluto las garantías para el mantenimiento de la paz y el aseguramiento de la vida biológica de los hombres, siendo el primer pensador que otorgó al poder político la potestad de regular y preservar la existencia orgánica de los individuos como el origen y el fundamento del Estado moderno. Hobbes establecerá sin embalajes las potestades del soberano dedicado a la gestión y preservación de la existencia biológica de los hombres como el fundamento que integra, legitima y mantiene el poder político. La defensa de la vida biológica y de los elementos que la integran hacen del pensamiento de Thomas Hobbes la llave para entender el surgimiento de la biopolítica en la modernidad.

\section{Conclusión}

Durante la Edad Media, el temor a perder la vida biológica se atenuaba por la conducción de esta desde el poder eclesiástico, albergando en los hombres la esperanza de entrar en el reino de los cielos, acogiendo la confianza de lograr la vida eterna junto con la divinidad cristiana, atemperando el deseo de satisfacer los placeres y permitiendo que el bíos fuera resguardado y regulado por los prelados religiosos. Posteriormente, cuando estas certezas se pierden en la nubosidad de las guerras de religión es que el miedo al castigo celestial se transforma en el espíritu de los hombres, moviéndose a buscar honores, riquezas y placeres sensuales que reafirmaban su vida biológica por encima de cualquier objetivo superior, pero ahora conservando el temor a perder su vida biológica que es finita y 
que es la única garantía de su existencia y de sus placeres y pasiones.

Es en estas entelequias que se fundará el Leviatán. La vida biológica se convertirá en el valor superior de los hombres y del Estado, y la muerte, o más bien el miedo a la muerte, en todo aquello que se deberá erradicar de la esfera pública y privada. El miedo sacrificará la libertad del estado de naturaleza y la igualdad originaria de los hombres como menciona Hobbes para instituir un poder superior que gobierne con la sola encomienda de preservar y conducir la vida biológica de los individuos. Por lo tanto, el miedo fundará la política en la modernidad, ya que a través de este sentimiento es que los hombres decidirán reunirse e instaurar un poder común, así como leyes y autoridades monopolizadoras de la violencia, siendo el miedo quien evitará la destrucción prematura de la vida biológica, así como su conducción por las instituciones estatales, quedando la libertad acosada constantemente por el poder político.

De esta forma, el Estado absolutista y la reforma protestante serán el umbral de la biopolítica, ya que estos colocarán los cimientos de los dispositivos que sostendrán este paradigma de dominación: desde la instauración de una fuerza coercitiva dependiente del soberano, la creación de una burocracia que dispondrá de una serie de medidas para el control de las poblaciones, la regulación sobre las actividades económicas, la crítica a los mecanismos de control sobre la vida biológica por las instituciones clericales, el desfallecimiento de los alcances de la vida eterna, hasta la restructuración del miedo ante la languidez de la vida supraterrenal promovida por el cristianismo, todos son elementos que conformaran al Estado moderno de una $u$ otra manera. Por lo tanto, la salud, la educación, el trabajo, la sexualidad, la reproducción biológica, la riqueza, las necesidades, las pasiones, las ambiciones, etc., serán espacios para la gestión del poder estatal y serán conducidos por los senderos que más convengan a las relaciones de dominación condensadas en torno al Estado moderno.

\section{Referencias}

Anderson, B. (1993). Comunidades Imaginadas. Reflexiones sobre el origen y la difusión del nacionalismo. México: Fondo de Cultura Económica.

Bayona, B., \& Souza, J. (2016). Iglesia y Estado. Teorías politicas y relaciones de poder en tiempo de
Bonifacio VIII (1294-1303) y Juan XXII (13161334). Zaragoza: Prensas Universitarias de Zaragoza.

Bayona, B., \& Souza, J. (2013). Doctrinas y relaciones de poder en el Cisma de Occidente y en la época conciliar (1378-1449). Zaragoza: Prensas Universitarias de Zaragoza.

Bertram, J. (1987). Alejandro V. Nueva York: Enciclopedia Católica.

Espitia, F. (2016). Historia del derecho romano. Bogotá: Universidad Externado de Colombia.

Fueyo, J. (1956). La morfología del poder político y la burocracia. Revista de administración pública, (20), 11-45.

Foucault, M. (2014) Sociedad, territorio, población. México: Fondo de Cultura Económica.

Galland, B. (1998). Les papes d'Avignon et la maison de Savoie: 1309-1409. Roma: École française de Rome.

Hoyt, R., \& Chodorow, S. (1976). Europe in the Middle Ages. Nueva York: Harcourt, Brace, Jovanovich, Inc.

Justiniano. (1889). I Instituta-Digesto. Cuerpo del derecho civil romano. Traducido al castellano del latino por Ildefonso García del Corral.. Barcelona: Consejo de Ciento.

Le Goff, J. (1982). La civilización del occidente medieval. Barcelona: Paidós.

Lutero, M. (2016). La libertad cristiana. California: Independently published.

Lutero, M. (2017). Manifiesto a la nobleza cristiana de la nación alemana. Ciudad de México: Editores Mexicanos Unidos.

Lutero, M. (2018). La cautividad babilónica de la Iglesia. Ciudad de México: Editores Mexicanos Unidos.

MacDonald, S., \& Charles, V. (1992). Ruler, Dynast and Defender of the Faith. Londres: Hodder \& Stoughton.

Maquiavelo, N. (1998). El Príncipe. Madrid: Editorial Espasa Calpe.

Marasco, R. (2012). Machiavelli contra governmentality. Contemporary Political Theory, 11(4), 339-361. https://doi.org/10.1057/cpt.2011.35

Mateu, J. (2007). Monoteísmo: Causas y efectos. Una respuesta al fundamentalismo religioso. Madrid: Libros en Red.

Mezzadri, L. (2001). Storia della Chiesa tra medioevo ed epoca moderna. Roma: Edizioni.

Mir, L. B.\& Dalcero, I. (2007). ¿Una diarquía medieval? El combate ideológico entre las dos espadas (500800). Departamento de Historia. Facultad de Filosofía y Letras. San Miguel de Tucumán: Universidad de Tucumán.

Mitre Fernández, E. (1986) El cisma de oriente y la configuración del dogma trinitario. Alcalá: Universidad de Alcalá. 
Petrucci, E. (1977). Ecclesiologia e politica di Leone IX. Roma: Editrice Elia.

Pounds, N. (1981). Historia económica de la Europa medieval. Madrid: Editorial crítica.

Rodríguez, G. \& Rigueirio, J. (2015). Manual de Historia Medieval Siglos III a XV. Mar del Plata: Giem Mar del Plata.

Romero, J. L. (1998) La Edad Media. Santiago: Fondo de Cultura Económica.

San Agustín (2017). Ciudad de Dios. México: Editorial Porrúa.

Sánchez, X. (1999). Iglesia, Imperio y poder en el primer tercio del siglo XIV. El enfrentamiento entre el papado, Luis IV de Baviera y los Visconti de Milán desde la iglesia de Santiago de Compostela. Anuario de Estudios Medievales, 49, 753798.

Schipani, S. (2016). El sistema jurídico romanístico y los códigos modernos. Lima: Fondo Editorial.

Svensson, M. (2019). Indiferencia, exilio y resistencia. El interim de Ausburgo como primera crisis global del protestantismo. Santiago: Universidad de los Andes.

Tomas de Aquino. (2003). Del ente y de la Esencia Del reino. Buenos Aires: Editorial Losada. 